\title{
Balancing Stakeholders' Interests In Evolving Teacher Education Accreditation Contexts
}

\author{
Alison Elliott, (Email: alison.elliott@cdu.edu.au), Charles Darwin University, Australia
}

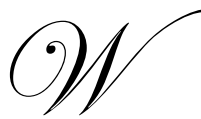

hile Australian teacher education programs have long had rigorous accreditation pathways at the University level they have not been subject to the same formal public or professional scrutiny typical of professions such as medicine, nursing or engineering. Professional accreditation for teacher preparation programs is relatively new and is linked to teacher registration which in itself is relatively recent in most jurisdictions. As elsewhere, the goal of accreditation is to enhance the overall quality of teacher preparation programs and to meet jurisdictional requirements for initial teacher competence.

Any new system of quality control takes time to develop and to embed into professional cultures and academic processes at the university or college level. Accreditation processes are no exception and Australia is grappling to develop procedures that meet jurisdictional legislative requirements, assure the public of the quality of teacher preparation and suit the professional context for each state. As yet these procedures have not focused on professional growth, accomplished or expert teaching, or quality within specific areas of preparation. While all agree that the ultimate goal of accreditation is quality assurance- to improve teaching quality in schools, negotiating optimum pathways to quality outcomes is no easy task in a country with an education system and population as diverse as Australia.

This paper considers some of the practical and institutional issues confronting teacher education providers as they come to terms with new regulatory environments that require external accreditation of teacher education to meet varying state and national policy agendas. Specifically, it focuses on issues engaging a small and regional teacher education provider, Charles Darwin University as it negotiates developing registration and accreditation requirements. It also flags the need to improve teacher quality through acknowledgement of advanced practice in teaching and expert performance in delivering teacher education.

Nationally, the minimum formal requirements for teacher credentialing is a four year degree qualificationeither in education or in a discipline based degree followed by a professional teaching qualification. At this point, Australian teacher education course accreditation processes are not well established. Accreditation has developed differently in each state and at different times. The states have different legislative and regulatory processes for accrediting initial teacher education courses and for registering teachers. There is no national consistency. Four states, South Australia, Western Australia, Tasmania and the Northern Territory, do not require formal 'accreditation' or approval of teacher education courses by the respective registration authorities per se, rather, they require teacher registration authorities and teacher education providers to 'confer', cooperate', 'collaborate', and/or 'liaise' in developing initial teacher education programs. Essentially, these states require teacher education programs to be 'endorsed' or 'approved' rather than 'accredited'. In both South Australia and Tasmania, the teacher registration authorities confer with institutions about course development to confirm that certain criteria, such as core subjects and minimum days of professional experience, are met. The specific processes for course endorsement are currently being fine tuned in the Northern Territory but they involve a process of collaboration followed by assessment.

\section{PRINCIPLES FOR TEACHER EDUCATION ACCREDITATION}

In the mid 1990s when accreditation was first seriously considered at a national level, six principles for accreditation systems emerged from discussions with experts and consultations with stakeholders. These were: 
- $\quad$ Need for a procedure which provides public assurance of initial teacher education programs, and thereby of the graduates of those programs.

- $\quad$ Procedures that provide for national accreditation, and are sensitive and responsive to local needs and circumstances, and locally accessible.

- Involvement of major stakeholders in a collaborative structure.

- $\quad$ Transparent, cost-effective, efficient and timely procedures that are integrated as appropriate with existing processes of accreditation and review.

- On-going cycles of review of the National Standards and Guidelines for Initial Teacher Education, the procedures of accreditation, and initial teacher education programs.

- $\quad$ Procedures that promote and support quality, diversity, innovation, and the networking of best practice in initial teacher education

Australian Council of Deans of Education (1997) Preparing a Profession. Report of the National Standards and Guidelines for Initial Teacher Education Project.

Although accreditation has developed on a state rather than national basis, and independently of the Australian Council of Deans of Education (ACDE) that established these broad principles, existing accreditation processes are generally consistent with the principles and with Australia's National Framework for Professional Standards for Teaching (2003).

\section{THE CURRENT ACCREDITATION LANDSCAPE}

While Australian teachers are normally well prepared for their teaching roles and students perform well in international tests of academic achievement such as PISA and TIMMS, there is considerable public pressure to strengthen teacher skill and improve student outcomes, especially school retention and especially for disadvantaged groups including Australian Indigenous students. At the core of Australian efforts to develop more regulated approaches to initial teacher preparation is boosting teacher quality, status and professionalism. It is generally believed that better quality teacher education programs and greater consistency across programs will impact positively on teacher quality and in the first instance on graduate teachers' initial competencies and classroom performance. Improved teacher education leading to better teachers is central to enhancing student learning and wellbeing. In the longer term maintaining and strengthening teacher quality is a key goal that has yet to be addressed seriously on a national basis.

Internationally, the concepts of teacher registration and teacher education accreditation are linked and well established. In Australia though, while there is a wide agreement that teacher education programs should be embraced within a legislated regulatory framework, the ways in which this regulation might be operationalized nationally, and even in some cases at a state level, are less well defined.

Presently, state-based accreditation of teacher education is firmly linked to teacher registration but the actual accreditation processes in most states are recent and still evolving, including in the Northern Territory. But before the paint is even dry on state-based accreditation, a complicating factor in the form of a proposed national teacher education accreditation system has emerged. Raised by a recently constituted and Federally funded professional umbrella organization for teachers Teaching Australia, this new accreditation possibility has added an additional layer of complexity to the already crowded arena of state-based accreditation including efforts by a consortium of teacher registration bodies to harmonize current state-based accreditation for a national context.

That national accreditation is on the agenda is not surprising. In today's political and educational climate, teacher registration and the accompanying moves to accredit teacher education courses are part of a wider movement by national government to ensure greater consistency in education across the country and assure better teachers and greater school accountability. Relatedly, formal measures to strengthen the quality and status of teaching has been of greater interest to the profession itself. Sentiments about enhancing quality are generally well accepted and embraced. However, there are national and local concerns about the possibility of multiple accreditation processes- state and federal, plus internal university based systems, on a number of fronts. As Charles 
Darwin University gears up for external teacher education accreditation- both state-based and possibly on a national front, careful consideration and balancing of state and national perspectives plus local conditions is required. Issues considered include:

- the role of academic autonomy in accreditation processes,

- duplication of existing internal accreditation processes,

- $\quad$ length of accreditation cycles,

- $\quad$ accreditation costs,

- ways of reporting accreditation status to the community and the impact of possible national ranking schemes,

- $\quad$ provisions for national consistency and mutual recognition (across states) of accreditation together with the importance of embracing local requirements,

- $\quad$ alignment of college graduate competencies with national and state-based teacher professional standards, sensitivity to local considerations such as Indigenous communities and learners from culturally and linguistically diverse backgrounds,

- $\quad$ balancing graduate outputs and program inputs and processes,

- the importance of collegiality and sharing ideas across institutions and jurisdictions,

- $\quad$ balancing external and internal standard setting and accreditation, and

- $\quad$ the operation of accreditation panels and processes.

Ideally, accreditation systems assure the states, teacher registration authorities, employers and the public that universities maintain acceptable and common course standards and that graduating teachers are prepared to provide quality learning environments for students, and this needs to be interpreted in the light of local needs and concerns. Importantly, as indicated by Ingvarson et al. (2006), teacher education accreditation frameworks must be explicit and transparent, designed in co-operation with key stakeholders, promote the ongoing quality enhancement of teacher education, ensure nationally aligned course standards and qualifications, and assure a uniform standard of graduate attributes and outcomes. Negotiating a shared understanding of the internal knowledge base for teaching and learning in dynamic and changing context, plus adding value to existing processes and procedures in the face of increasing demands within the tertiary education sector is no easy task. Just what teachers should know and be able to do at the beginning of their careers is by no means certain and as understandings of best practice evolve and adapt to local contexts they will influence the framework for teacher education and by definition, the standards and expectations for initial teacher education courses.

In attempting to ensure teachers are well prepared for local contexts, the Northern Territory-based teacher education endorsement system regards local interests such as Indigenous education and diversity highly. Developing the endorsement framework and processes has been a collaborative yet rigorous venture in conjunction with local teacher education providers and stakeholders sensitive to local needs. New efforts to develop a national system of teacher education accreditation outside state based processes raise substantial issues about contextualizing teacher preparation and professionalism as well as more operational issues. Further, at this stage, links between state and national accreditation both philosophical and logistical are not well defined and there is no provision to acknowledge program distinctiveness or quality delivery. Similarly, ways of supporting teachers to progress from minimum standards and competencies to accomplished or expert practice need articulation.

\section{TENSIONS}

There has long been interest in developing more nationally consistent approaches to education and regulatory frameworks in Australia. It is often argued that a country as small as Australia - just 20 million peoplebut with high internal mobility, needs a nationally consistent education system with common school starting ages, duration of schooling, curriculum and certification. Clearly, national accreditation has a number of positive dimensions in promoting national education initiatives such as curriculum and assessment regimes, but while education systems are state based and funded and locally operated, achieving national consistency across any dimension of schooling is challenging and often resisted at a number of levels, including from within teacher education faculties. 
There are strong tensions for teacher education providers in considering and planning for accreditation possibilities and balancing national and local considerations and imperatives in a state funded and regulated and highly localized schooling environment. Today, most education faculties operate on a national scale enrolling students from around the country and overseas. Improved technologies make external (distance) education much more attractive to students. From a community and employer perspective, national accreditation possibilities can also be attractive in a small and hard-to-staff jurisdiction such as the Northern Territory. Because of its remoteness from the main population centers of Sydney, Brisbane and Melbourne the Northern Territory has difficulty recruiting and retaining teachers. Most, some $70 \%$, are recruited from elsewhere and remain in the Territory for just a few years. Clearly, there would be considerable benefits in national education policies and practices from an operational perspective.

From the university perspective, nation-wide local jurisdictional requirements regarding curriculum, practice teaching, and teaching standards present continuing challenges. At the same time there is a clear understanding of the need to meet NT teaching standards in course delivery. Academic staff want to ensure that teachers entering the profession are equipped with the knowledge, skills and professional standards and ethical behavior which schools and communities require and their concerns extend beyond their immediate local jurisdictional contexts. Critically, a University such as Charles Darwin is reluctant to embark on new national accreditation processes at a time when state-based processes are being refined. While a national accreditation program is likely to promote greater consistency in teacher education curriculum and teaching standards across courses and jurisdictions and would require more comparable levels of graduate skills and competencies it would also require close attention to local issues. At present though, there is little consistency between universities in student teachers' experiences or in ways of assessing their progress toward meeting standards.

\section{STRUCTURE}

As mentioned, registration and accreditation go hand in hand at the state level but how a national accreditation system could or might sit with existing processes is less clear. Current state-based accreditation has a regulatory function that cannot be readily dismantled or subsumed by a national system. It is possible that a national accreditation process independent of state processes could transform into a role more akin to a certification system to promote and recognise expert professional preparation and development. There is an important role to be played in recognising and celebrating quality preparation of teachers and the distinctiveness, specialisation and expertise within courses- such as for early childhood, primary or secondary teaching or in disciplines. National accreditation could become a voluntary (or perhaps mandatory) approach to performance assessment within programs against profession-wide standards.

Certification of distinction and quality within programs is something that might complement and add value to existing regulatory regimes. The notion of certification of individual professionals is common to many professions, but not to teaching. Certification recognising teaching expertise could serve to improve teaching beyond initial graduate standards. Certification of program quality and distinctiveness would help teacher education providers maintain continuing high standards and improve quality in a critical area and competitive environment. However, developing and implementing a national system of certification for teachers or teacher education would take some time and complementing existing state and employer-based processes and building acceptance, usefulness and credibility, rather than merely duplicating or competing with current approaches requires careful planning.

While voluntary quality improvement processes might well be desirable, voluntary processes of accreditation or certification to recognize expertise or advanced performance are likely to work only when there is strong demand for teachers and this is unlikely to occur in small regional colleges such as Charles Darwin University. Any system that doesn't link registration and accreditation or tie accreditation or certification to some other mandatory requirement such as federal funding is vulnerable. Unless accreditation (or certification) is tied to federal funding for universities, for example for funding professional experience (in-school practice) or professional development, there will be little motivation and scant resources to engaging in such an exercise. 


\section{RECOGNIZING EXPERTISE AND ENHANCING QUALITY}

Planning for the introduction of accreditation of teacher education at Charles Darwin University is requiring some shifts in thinking about course delivery and structure. As a new initial teacher education course rolls out over 2007 to 2009 the overall course and each unit now needs explicit attention to meeting professional teaching standards, 'What teachers know and can do' to meet the standards has become a central concern and a starting point for explicating a professional learning continuum including recognition and certification of expert performance.

While the Northern Territory professional teaching standards are beginning to act as guide for initial teacher training teacher at Charles Darwin University there is growing interest in the pathways between these 'minimum standards' for beginning teachers and the standards expected for advanced practice. The Northern Territory state department of education designates a small number of teachers as 'exemplary' practicing teachers and rewards them accordingly, but there is no overall state or national processes for acknowledging or rewarding maturing or expert capability. Certainly, minimum standards are necessary, but clear indications of the relationships between quality teaching and enhanced student outcomes indicate the need to move beyond minimum practice standards. Career development and professional expertise should be on a continuous growth trajectory. A national system of certification for accomplished teachers together with recognition of quality teacher education programs and delivery aligned with or underpinned by mandated participation in on-going professional learning may well be a mechanism for improving teacher quality that complements existing registration and accreditation processes. Whatever the processes for building professional expertise beyond initial professional competencies, standard setting for recognition and certification of accomplishment - either individual or institutional- must be developed, owned, implemented and monitored by the profession. A system of certification that recognizes expertise at the school or university (course) level would add value to existing regulatory processes by building on graduate competencies and developing initial professional standards. As such it may well be suited to national implementation. Importantly, a national certification process would be well poised to build on the momentum of quality improvement inherent in new teacher education accreditation processes. As in the US, advanced certification at the individual would recognize teaching expertise, and link quality and remuneration. At the institutional level it could be linked to enhanced resources. Recognition and certification of advanced practice also has the flexibility to be discipline or teaching area specific, a dimension not yet evident in current teacher registration or teacher education accreditation but one that would be welcomed, certainly by teacher educators.

Finally, while the issue of preparedness for teaching is central to institutional accreditation initiatives, to date there appears to be no evidence of the impact of external accreditation processes on graduate teacher competence or developing practice. For example, there are no comparative data on the relative quality of graduate teachers from Queensland with a long history of teacher registration and accreditation and those from NSW or the NT where registration and accreditation commenced just recently. In fact, a recent study of Queensland school principals indicated that in their opinion, just $40 \%$ of recently graduated teachers had the competencies they deemed necessary for a beginning teacher (Ingvarson et al., 2005). And this is despite well established accreditation processes.

Importantly, beginning teachers need support to forge initial teaching competence and develop professional expertise. There is need for a system of quality improvement and renewal that moves beyond minimum teacher competence and basic accreditation of teacher education courses. Certification of advanced practice- whether for teachers or teacher education providers, and especially building teacher quality through strategic professional learning partnerships with teacher education institutions has the ability to drive quality enhancement and transcend the conventional parameters of professionalism. In teacher education, as we work toward bedding down a process of state-based accreditation, thinking ahead to ways of recognizing program distinctiveness and expert delivery is important for longer term building and enhancing teacher quality on a national front.

Paper presented at the College Teaching and Learning Conference, Venice, June 2007 


\section{REFERENCES}

1. ACDE (1997). Preparing a profession report of the National Standards and Guidelines for initial teacher education project, Canberra: ACDE).

2. Ingvarson, L., Elliott, A., Kleinhenz, E., \& McKenzie, P. (2006). Toward a national approach to the accreditation of pre-service teacher education. Melbourne: ACER.

3. Ingvarson, L., Beavis, A., Danielson, C., Elliott, A., and Ellis, A. (2005). An evaluation of the Bachelor of Learning Management at Central Queensland University. Canberra: DEST

4. Ministerial Council of Education, Employment, Training and Youth Affairs (2003). National Framework for Professional Standards for Teaching. Canberra: MCEETYA.

\section{NOTES}

